\title{
Trade-offs between timber production, carbon stocking and habitat quality when managing woodlots for multiple ecosystem services
}

\author{
SOPHIE CARPENTIER ${ }^{1 *}$, ELISE FILOTAS ${ }^{2}$, I. TANYA HANDA ${ }^{1}$ AND \\ CHRISTIAN MESSIER ${ }^{1,3}$ \\ ${ }^{1}$ Centre for Forest Research, Department of Biological Sciences, University of Québec, Montréal, Québec H3C3P8, \\ Canada, ${ }^{2}$ Téluq, Université of Québec, Montréal, Québec H2S 3L5, Canada and ${ }^{3}$ Institute of Temperate Forest \\ Science (ISFORT), University of Québec in Outaouais, Ripon, Québec F0V1V0, Canada
}

Date submitted: 1 October 2015; Date accepted: 26 August 2016; First published online 11

November 2016

THEMATIC SECTION

Forest Ecosystem Services

\section{SUMMARY}

Managing for multiple ecosystem services is a growing issue for forest managers. As trade-offs arise between conflicting management objectives, stakeholders must be informed of the possible outcomes of alternative choices in order to facilitate decision-making. We modelled stand dynamics under single-management and functional zoning multiple-management (TRIAD; i.e. three-zone) scenarios in different forest types typical of eastern North America with the Forest Vegetation Simulator (FVS). Timber production, carbon stocking and habitat quality ecosystem services were calculated with simulation outputs. Habitat quality was measured using a habitat suitability index that integrated stand structural indicators. A multicriteria decision analysis (MCDA) was performed in order to rank scenarios. We show that the most intensive management yielded greater timber volumes but resulted in the weakest carbon and habitat quality scores. The TRIAD scenarios in sugar maplebeech stands offered the best compromise in services compared to single management. In shade-intolerant deciduous stands, there was a loss of timber production with TRIAD scenarios, but greater carbon stock and habitat quality were observed. Our study contrasts alternative management scenarios for ecosystem services in woodlots of different forest types. It confirms that multiple harvest systems better achieve multiple services. The coupling of simulation modelling with MCDA offers a simple and flexible method to help stakeholders and managers make sound decisions.

Keymords: ecosystem services, forest dynamics modelling, forest management planning, multi-criteria decision analysis, TRIAD

\footnotetext{
*Correspondence: Sophie Carpentier e-mail: sophie.o.carpentier@ gmail.com

Supplementary material can be found online at http://dx.doi. org/10.1017/S0376892916000357
}

\section{INTRODUCTION}

Forests are under increasing pressure to provide a multitude of ecosystems services (i.e. direct and indirect goods and benefits for humans), such as timber, carbon, recreation and biodiversity (Costanza et al. 1997), to a growing population. Tree carbon storage, for example, is now recognized as an important forest function that contributes to mitigating climate change (Canadell \& Raupach 2008). Different forest management practices can either fix or release carbon (Dixon et al. 1994), making carbon accounting important (Moore et al. 2012) and furthermore necessary through carbon markets (Tavoni et al. 2007). Habitat quality - a well-used indicator of the potential of a habitat to harbour local biodiversity reflects ecosystem integrity and is part of forest certification requirements (Brown et al. 2001). An ecosystem with high habitat quality contributes better to overall ecosystem function and service provision, including cultural services such as recreation (Balvanera et al. 2006). Strong trade-offs among supply, regulation and cultural ecosystem services have been identified (Bradford \& D'Amato 2011), yet few tools and approaches exist to help private forest owners and managers integrate multiple management objectives in their forests.

One such tool - forest simulation modelling - is used to predict, within uncertainty boundaries, the dynamics and the possible outcomes of various management decisions on forests (Peng 2000; Messier et al. 2003). However, wellinformed management decisions based on the interpretation of several simulation outputs can be overwhelming, particularly when comparing the success of various management scenarios in achieving different management objectives (Mendoza \& Martins 2006). This is why multi-criteria decision analysis (MCDA) has been proposed to improve the structuring and understanding of complex management scenarios with several management objectives (Belton 2002).

Combining simulation modelling and MCDA, our study aimed to quantify the trade-offs between three important ecosystem services resulting from different forest management practices so as to provide decision-making tools for stakeholders. We compared the levels of timber production, carbon storage and habitat quality (henceforth 
referred to as a service) under various single- and combinedmanagement scenarios, using forest stand characteristics produced by the growth simulation model Forest Vegetation Simulator (FVS). We used a simplified MCDA approach on model output by Schwenk et al. (2012). Habitat quality was measured with a habitat suitability index (HSI) that we developed in order to use the FVS outputs directly, thus simplifying the overall process for the potential users of this approach. Furthermore, we used five stands from three forest types in order to cover a realistic range of stands encountered in eastern North America. Sugar maple-beech (SM) stands, shade-intolerant deciduous (SID) stands and white spruce plantations (WSP) were each simulated under three alternative, increasing intensity, single-management scenarios. We extended the management possibilities seen in Schwenk et al. (2012) by calculating five functional zoning multiple-management scenarios, hereafter named TRIAD (i.e. three-zone) scenarios (sensu Messier et al. 2009). Similar to the compartment model described by Odum (1969), each TRIAD scenario combines all ecosystem service results with three different proportions of intensive, extensive and nomanagement zones.

The goals of our study were to: (1) simulate the effects of contrasting management scenario intensities applied in three different forest types on multiple services; (2) quantify tradeoffs in ecosystem services; and (3) estimate whether TRIAD scenarios could better fulfil multiple services at a time. To our knowledge, this is the first analysis comparing multiple ecosystem services that combined even- and uneven-aged management prescriptions within different forest types and contrasting management scenarios.

\section{METHODS}

\section{Study region and stands}

Our modelling approach explores stands that one could encounter in a typical private hardwood forest of eastern North America. Stands of SM, SID and WSP were selected for the simulation of various forest management scenarios.

Stands from the Forest Inventory and Analysis (FIA) database of the state of New York (2012 survey) were used to make the simulation as realistic as possible. To simplify the number of simulations to be made and render all scenarios more easily comparable, we decided to select stands that were ready to harvest, resulting in a bank of suitable stands from which to draw five stands randomly. The criteria for stand selection are described in Appendix S1 (available online) and their silvicultural characteristics are shown in Table S1.

\section{Forest simulation model}

The Northeast Variant of FVS, a well-known growth model (Crookston \& Dixon 2005), was used to simulate three management scenarios, with different harvest types and cycles, applied on the stands described above. FVS simulates the dynamics of each tree in a stand in a non-spatially explicit context.

\section{Management scenarios and simulation parameters}

Management scenarios were simulated over a 70-year horizon using 10-year time steps. The first three scenarios were designed to replicate management that is typical of Northeast American forests. An ecosystem (Grumbine 1994) and intensive management scenario that differed depending on forest type was compared to a no-management scenario (where no timber is cut) for each of the three different forest types (scenarios hereafter named No-management, Ecosystem, and Intensive; see Table 1). The scenarios and the rotation lengths were developed in order to reflect the current thinking in terms of silvicultural practices for these kinds of stand in private woodlots.

Harvesting parameters for the individual tree selection (ITS) used for Ecosystem in SM stands were set in order to allow for initial basal area recovery in a 20 -year harvest cycle. The merchantable volume of a tree was calculated from 15-cm stump height trees with a minimal diameter at breast height (DBH) of $9 \mathrm{~cm}$. The maximum basal area was set at $35 \mathrm{~m}^{2} \mathrm{ha}^{-1}$ in the SM stands, representative of forests dominated by sugar maple and beech (McCune \& Menges 1986), at $40 \mathrm{~m}^{2} \mathrm{ha}^{-1}$ for the denser SID stands and at $50 \mathrm{~m}^{2}$ $\mathrm{ha}^{-1}$ for the WSP. Setting a maximum basal area ensured that the stands would not grow to exceed what is sustainable for the site, which has been recommended for FVS (Dixon 2002).

TRIAD forest management scenarios consisted of simultaneously applying the three simulated management scenarios (shown in Table 1 for SM and SID) within one single stand of a particular forest type. The mean of the five stands under each single-management scenario was used for this single stand in order to simulate the various TRIAD scenarios. Spatial components were not considered. The 'wood production' zone corresponded to our Intensive, which was divided into two sub-zones: the original stand under Intensive and a WSP under Intensive. The latter was implemented following a clearcut in the SM and SID stands. Following Côté et al. (2010), we investigated five different zoning proportions (Table 2). The numbering in the names of the TRIAD scenarios reflects the percentage of the land set aside for conservation, increasing from T12 to T50. The zoning proportions of T12 and T20 have been tested by Côté et al. (2010) and T50 is currently demanded in boreal forests by some environmental groups (Badiou et al. 2013).

\section{FVS simulation cycles and regeneration sub-model}

There is a fixed processing sequence of operations in a FVS simulation (Dixon 2002): the model first reads and computes the initial stand characteristics, then processes the thinning if requested, grows trees, allows some mortality that generates 
Table 1 Management scenarios for the 70-year simulations (2012-2082). Retention harvesting refers to $80 \%$ of the basal area being removed from below. Commercial thinning refers to $35 \%$ of the basal area being removed from above. Pre-commercial thinning refers to $10 \%$ of the basal area being removed from below. DBH = Diameter at breast height; ITS = Individual tree selection.

\begin{tabular}{|c|c|c|c|}
\hline Management scenario & Sugar maple-beech stands & $\begin{array}{l}\text { Shade-intolerant } \\
\text { deciduous stands }\end{array}$ & White spruce plantations \\
\hline No-management & No management & No management & No management \\
\hline Ecosystem management & $\begin{array}{l}\text { ITS every } 20 \text { years: q-factor: } 1.4 \text {; } \\
\text { min DBH class: } 5 \mathrm{~cm} \text {; max } \\
\text { DBH class: } 61 \mathrm{~cm} \text {; DBH class } \\
\text { width: } 5 \mathrm{~cm} \text {; residual basal } \\
\text { area: } 21.6 \mathrm{~m}^{2} \mathrm{ha}^{-1}\end{array}$ & Retention harvesting: 20 & 12, 2082; commercial thinning: 2052 \\
\hline Intensive management & \multicolumn{2}{|c|}{$\begin{array}{l}\text { Clearcut: } 2012,2082 \text {; pre-commercial thinning } 20 \text { years } \\
\text { after clearcut: } 2032 \text {; commercial thinning } 40 \text { years after } \\
\text { clearcut: } 2052\end{array}$} & $\begin{array}{l}\text { Pre-commercial thinning: } 20 \text { years after } \\
\text { seedling plantation; Commercial thinning } \\
30 \text { years before clearcut: } 2052 \text {; Clearcut: } 2082\end{array}$ \\
\hline
\end{tabular}

Table 2 Proportions (\%) allocated to each TRIAD management scenario (modified from Côté et al. (2010)).

\begin{tabular}{llllc}
\hline \hline & & \multicolumn{2}{c}{ Wood production zone } \\
\cline { 3 - 5 } TRIAD scenario & No-management zone & Ecosystem management zone & Intensive & Plantation-Intensive \\
\hline T12 & 12 & 74 & 10 & 4 \\
T20 & 20 & 40 & 36 & 4 \\
T33 & 33 & 25 & 17 & 17 \\
T50 & 50 & 25 & 25 & 0 \\
T50I & 50 & 13 & 12 \\
\hline \hline
\end{tabular}

Table 3 Measures of ecosystem services on 70-year simulation results. DBH = Diameter at breast height; FVS: Forest Vegetation Simulator.

\begin{tabular}{ll}
\hline \hline Ecosystem service & FVS output measure \\
\hline $\begin{array}{l}\text { Timber } \\
\text { Carbon storage }\end{array}$ & $\begin{array}{l}\text { Total merchantable volume harvested over } 70 \text { years }\left(\mathrm{m}^{3} \mathrm{ha}^{-1}\right) \\
\text { Mean carbon stocked in aboveground live trees, standing dead trees and down dead wood }(\text { tons ha }\end{array}$ \\
$\begin{array}{l}\text { Habitat quality } \\
\text { Vertical structure }\end{array}$ & Mean Gini index \\
Large tree density & Mean number of trees of DBH $>40 \mathrm{~cm}($ trees ha-1) \\
Large snag density & Mean number of standing soft and hard snags of DBH $>30.5 \mathrm{~cm}\left(\operatorname{trees~ha~}^{-1}\right)$ \\
\hline \hline
\end{tabular}

snags and finally establishes new trees (regeneration). As mortality is density dependent, parameters of new seedling regeneration must be computed in order to ensure proper forest dynamics (see Table S2) (Nunery \& Keeton 2010). The parameter selection and adjustment for the model are described in Appendix S1.

\section{Ecosystem service measurements and utility analysis}

We limited our analyses to three services that could be easily assessed using only the variables included in FVS. Timber, habitat quality and stored carbon were calculated based on the FVS outputs for the different stands (Table 3). Timber is a common source of revenue for forest owners, habitat quality is an expected requirement of many certification programmes and carbon is increasing in importance and value. All merchantable volumes that were removed were summed over the 70-year simulation for the timber service. It was equal to zero in No-management, as no merchantable volume was extracted. We used the sub-model Fire and Fuels Extension of FVS in order to evaluate carbon storage. The default 10-year time step was used for all of the simulation outputs (Wykoff \& Crookston 1982). We considered only the carbon stored in the aboveground live tree biomass and followed the carbon calculation of Jenkins et al. (2003).

Habitat quality was quantified with a HSI (Schamberger \& Krohn 1982) based on measurable structural components of a forest stand (Ferris \& Humphrey 1999). Three characteristics of old-growth forests were considered as optimal in the calculation of the HSI for each stand (Bauhus et al. 2009). The densities of large trees $(\mathrm{DBH} \geq 40 \mathrm{~cm})$ and large snags $(\mathrm{DBH}$ $\geq 30.5 \mathrm{~cm}$ ) were averaged over the simulation. Furthermore, since tree diameter distribution is a good indicator of stand 
biodiversity (Buongiorno et al. 1994), it was calculated using the Gini index (Gini 1921) on DBH classes of 2 inches $(5.08 \mathrm{~cm})$. This coefficient has been found to be particularly appropriate for discriminating diverse stand parameters, such as its vertical structure (e.g., Bílek et al. 2013).

The MCDA approach allows for the determination of which alternative scenario performs best considering multiple services, as well as for visualizing the trade-offs and benefits among them (Diaz-Balteiro \& Romero 2008; Ananda \& Herath 2009). Each service was designated as a partial utility scaled to 1 , or $100 \%$, to allow for comparison among them. Partial utilities can be weighted depending on the priorities and values of the manager. Among the many multiple-criteria decisionmaking techniques available (Tamiz et al. 1998; Romero 2001; Belton 2002), we used a simple methodology fit for a discrete-choice problem like ours. The overall performance of a scenario was quantified by the sum of the service levels transformed into partial utilities.

In this study, we gave services equal weights. For each of the three stand types, partial utilities were calculated as:

$$
U_{P, i, j}=\frac{P_{i, j}}{P_{\max }}
$$

for all three services $P$, five stands $i$ and three management scenarios $j$. To obtain the carbon stock utility, $U_{C s t o c k, i, j}$, every carbon stock annual mean for an $i, j$ combination, Cstock $k_{i, j}$, was divided by the maximum value of the annual mean carbon stock, Cs to $c k_{\max }$, found among the five stands $i$, across all three management scenarios $j$. Likewise, for the timber utility $U_{T, i, j}$, the value of the total harvested volume after 70 years of every $i, j$ combination, $T_{i, j}$, was divided by the maximum value showed by any combination $i, j, T_{\max }$.

Habitat quality was measured with a HSI, $H_{i, j}$ :

$$
H_{i, j}=U_{L T, i, j}+U_{L S, i, j}+U_{G, i, j}
$$

where sub-utilities (density of large trees $U_{L T, i, j}$, density of large snags $U_{L S, i, j}$ and Gini coefficient $U_{G, i, j}$ ) were obtained with eqn (1) using HSI components instead of $P$ services. Following eqn (2), the partial utility of habitat quality, $U_{H, i, j}$, was then calculated with eqn (1).

Finally, for every management scenario $j$, the partial utilities of the five stands $i$ of a specific type (SM, SID or WSP) for a service $P$ were averaged, giving a mean utility $U_{P, j}$ :

$$
U_{P, j}=\frac{\sum_{i=1}^{5} U_{P, i, j}}{5}
$$

The TRIAD management scenarios were evaluated with eqn (3) in the SM and SID stands. The calculation of a total score $U_{P}$ Tot for a given service $P$ was realized by using the proportions $p$ found in Table 2 to weight each mean utility $U_{j}$ :

$$
\begin{aligned}
U_{P T o t}= & p_{N M} U_{P, j=N M}+p_{E C O} U_{P, j=E C O} \\
& +p_{I N T} U_{P, j=I N T}+p_{P I} U_{W S P, P, j=I N T}
\end{aligned}
$$

where $p_{N M}, p_{E C O}$ and $p_{I N T}$ are the proportions of the utility value $U$ for No-management, Ecosystem and Intensive, respectively. In eqn (4), $p_{P I}$ refers to the proportion of the partial utility found for the most timber-productive WSP stand under Intensive.

Simulation outputs were analysed by first computing utilities for single-management scenarios. All TRIAD scenarios and single-management scenarios were then compared with respect to every utility using MCDA. A non-parametric Kruskal-Wallis test $(\alpha=0.05)$ was used in order to test the differences between single-management scenarios within a forest type. Post hoc contrasts were performed when necessary with pairwise comparisons using a multiple comparison test after Kruskal-Wallis testing ( $R$ package 'pgirmess'). All of the FVS output data analyses were conducted with R (R Development Core Team 2010).

\section{RESULTS}

\section{Simulated stand characteristics over a rotation}

Live tree basal area (Fig. 1), aboveground carbon and available merchantable volume (similar pattern as basal area; see Fig. S1) changed over the rotation according to the harvesting interventions that were planned. In all forest types, Nomanagement maintained the highest values for all three stand characteristics. Ecosystem and Intensive were very similar except for the SM forest type, where Ecosystem tended to maintain higher values throughout the rotation (Table 1). The fluctuating values for the two management scenarios reflected the scheduled harvests and density-dependent mortality. In fact, after the first cutting event in 2012 in managed stands, the levels of carbon and available merchantable volume never reached those of unmanaged stands. In SM stands, stored aboveground carbon at the end of No-management was twice the highest value of carbon stored during the rotation under Intensive (Fig. S1(al)).

Sharp increases in the basal area of SID stands under active scenarios after the first harvest were caused by a massive recruitment of seedlings, of which a large proportion died in the following time step due to density-dependent mortality (Fig. 1(b)). This heavy mortality explained the drop in 2032 for basal area and carbon values in Ecosystem, while the drop in Intensive also resulted from a pre-commercial thinning. Both scenarios in SID stands showed almost the same amounts of carbon throughout the rotation (Fig. S1(a2)).

\section{MCDA for single-management scenarios}

As expected, harvest volume increased with increasing management (Fig. 2, Table S3). The most timber for all forest types was harvested under Intensive, although the overall model was significant $(p<0.001)$ only in the SM forest type, in which more than 2.5-times the amount of timber was harvested compared with Ecosystem management. Timber utility in the latter scenario resulted in $25 \%$ of the maximum timber being produced (Fig. 2(a)) compared to $67 \%$ for Intensive. 

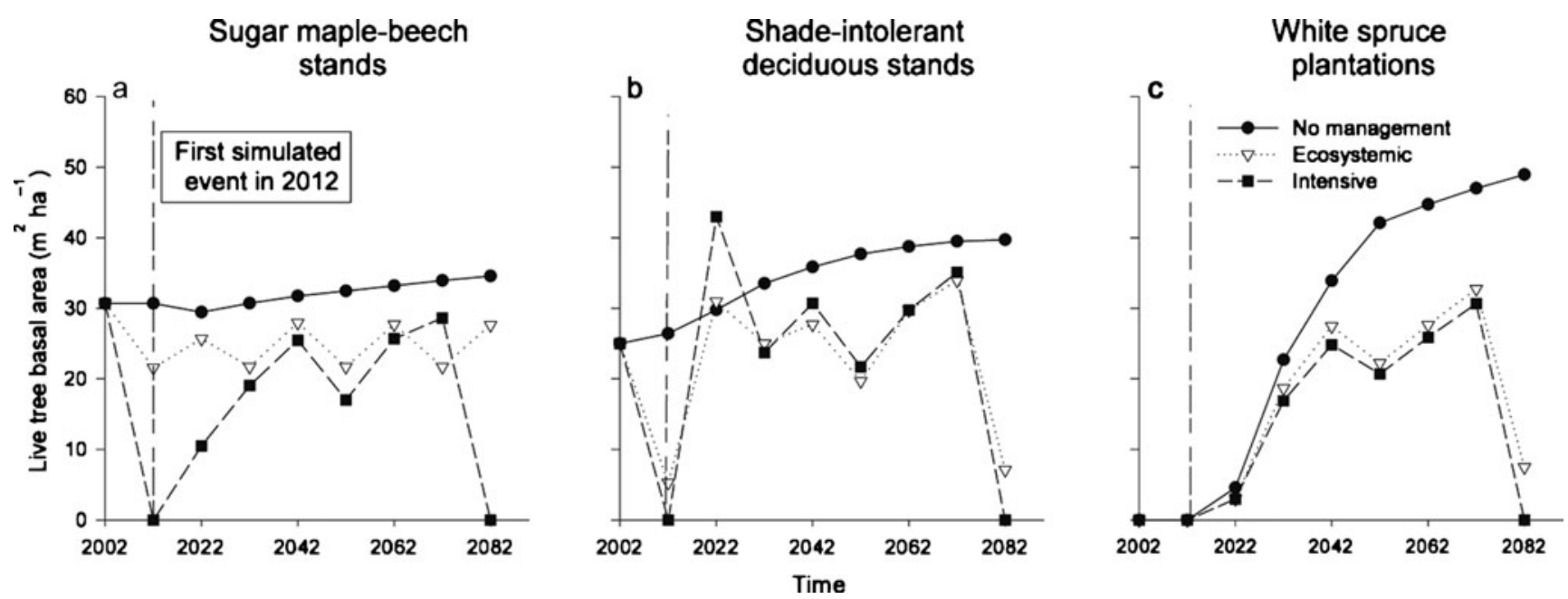

Figure 1 Results of the 70-year simulation (2012-2082) with 10-year time steps, averaged over (a) five sugar maple-beech stands, $(b)$ five shade-intolerant deciduous stands and $(c)$ five white spruce plantations for three management scenarios. Measurements shown are the mean live tree basal areas calculated after harvesting activities if scheduled. Values in 2002 for $(a)$ and $(b)$ were calculated using the predicted 70 -year rate of change in the No-management scenario. The null values in 2002 for $(c)$ represent the stand after a clearcut, at the beginning of the next rotation. These 2002 values are for visual purposes and are not used in subsequent analyses.

\section{a) Sugar maple-beech stands}

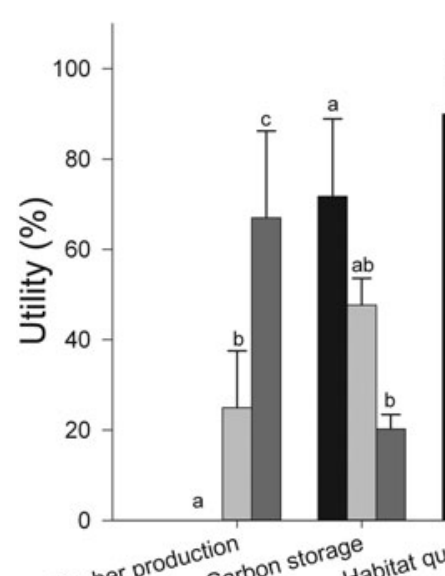

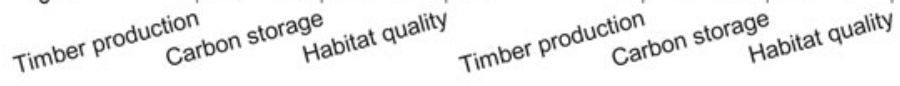

b) Shade-intolerant deciduous stands

\section{c) White spruce plantations}

\section{Management scenario}

Figure 2 Expected mean utilities \pm SD for timber production, carbon storage and habitat quality over the 70-year rotation for the No-management, Ecosystem and Intensive management scenarios applied in $(a)$ sugar maple-beech stands, $(b)$ shade-intolerant deciduous stands and $(c)$ white spruce plantations ( $n=5$ for each forest type). Utilities are service values relative to each other, where the maximum value reached by any combination of a single stand for any of the three management scenarios is given $100 \%$. For each management scenario within each forest type, a different letter ( $a, b$ or $c)$ above the bars indicates a significant difference between utility values.

For carbon storage, No-management resulted in higher utilities than the two other scenarios for all three forest types, though this was only significant when compared to Intensive $(p<0.05$; Fig. 2, Table S3). In SM stands, the predicted mean carbon storage utility was of $72 \%$ for Nomanagement, which is 50 and $300 \%$ higher than Ecosystem and Intensive, respectively (Fig. 2(a)). In turn, Ecosystem stored more aboveground live carbon than Intensive.
In the SID and WSP stands, No-management achieved a carbon utility of more than twice the utilities found under the active scenarios (Fig. 2(b) and (c)).

The utilities for habitat quality displayed similar patterns as for carbon storage in the SM and SID stands (Fig. 2(a) and $(b))$. In SM stands, while No-management produced a greater habitat quality utility score than Ecosystem, the difference was significant between No-management and 

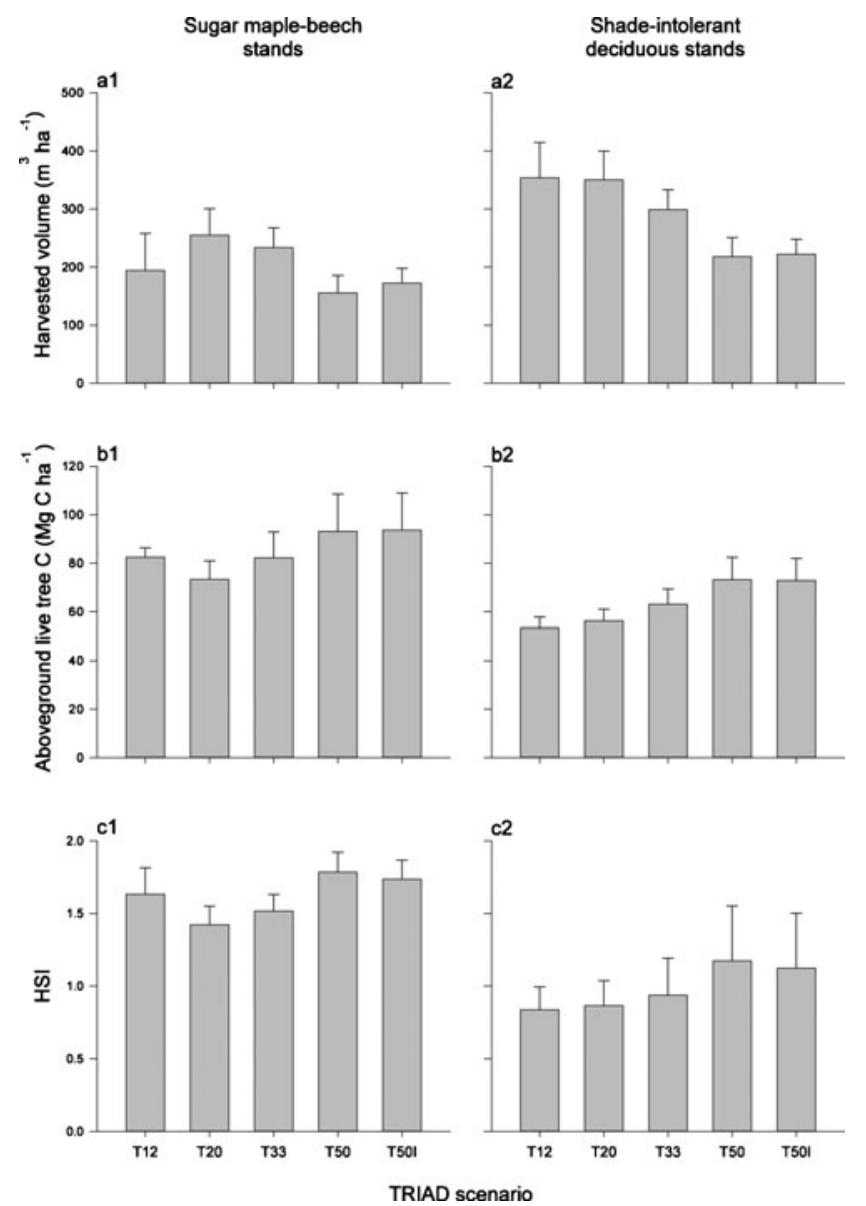

Figure 3 Comparison of (a) total harvested volume (mean $\pm \mathrm{SD}$ ), $(b)$ carbon $(\mathrm{C})$ stored in aboveground live trees biomass and $(c)$ habitat suitability index (HSI) among the five TRIAD scenarios in (1) sugar maple-beech and (2) shade-intolerant deciduous stands. The results are based on the 70-year means obtained from single-management scenarios (Table S3), multiplied by their assigned proportion within the multiple-management TRIAD scenarios. The results of all of the single-management scenarios are then summed within each TRIAD scenario.

Intensive only ( $p<0.05$; Fig. 2(a)). In SID stands, habitat quality was significantly greater under No-management than under Ecosystem or Intensive scenarios ( $p<0.05$; Fig. 2(b)). Unmanaged stands displayed large variability in habitat quality and their mean utility score reached $56 \%$, which did not differ significantly from Ecosystem despite a lower utility score $(26 \%)$, but was more than double that of the Intensive scenario $(20 \%, p<0.05$; Fig. 3(b)). In WSP stands, while habitat quality had a higher utility score under Nomanagement (57\%; Fig. 2(c)), none of the scenarios resulted in significant differences. Like the available merchantable volume and carbon stocks, habitat quality (higher density of large trees and snags and greater Gini index) was greatest in No-management during the whole rotation in all stands (see Fig. S2 for the utility results of HSI components). The mean HSI was very low in unmanaged WSP stands and almost null in managed ones (Table S3) due to their poor vertical structure. None of the WSP stands had large trees or snags throughout the rotation, so the HSI was based only on the Gini index (Fig. S2).

\section{MCDA for single- and multiple-management TRIAD scenarios}

The different TRIAD scenarios resulted in different values of ecosystem services for each forest type (Fig. 3). The highest timber production, carbon storage and habitat quality were found in the T20, T50I and T50 scenarios, respectively, for the SM forest type, and in the T12, T50I and T50 scenarios, respectively, for the SID forest type. Indeed, a decrease of timber production (Fig. 3(al) and (a2)) echoed a reverse tendency in carbon storage (Fig. 3(b1) and (b2)) and habitat quality (Fig. 3(cl) and (c2)).

Finally, trade-offs were observed among the utility values for timber, carbon and habitat quality produced under the single management scenarios (No-management, Ecosystem and Intensive) and the five TRIAD scenarios (Fig. 4). Clearly, no scenario can be singled out for the optimized production of all three services. While the No-management scenario produced the highest habitat quality and carbon utilities, it did not produce any timber (Fig. 4). Conversely, while the Intensive management scenario had the highest timber utilities, it also had the lowest habitat quality and carbon utilities. Despite showing the highest total utility, Nomanagement did not produce timber, hence it cannot be seen as the best compromise between the three services. The best compromise among ecosystem services was found with the TRIAD T50I scenario in SM stands and the T50 scenario in SID stands, which resulted in the highest scores for the provision of all three services. The lowest utility scores were observed in Intensive and Ecosystem single-management scenarios.

\section{DISCUSSION}

This study presents a straightforward approach to identifying and quantifying trade-offs among three important ecosystem services - timber, carbon and habitat quality - under commonly used management scenarios. The different harvesting schedules and intensities on three types of forest stands highlighted the variability of responses to management practices. The MCDA approach helped assess and compare the overall performances of different management scenarios for these three services and revealed the best, average and worst management options for each service individually; this is valuable information in the decision-making process of managers.

\section{Evaluation of each ecosystem service}

\section{Timber production}

The measure of timber volume is largely used by foresters and is the easiest to grasp by stakeholders. However, timber 
a) Sugar maple-beech stands

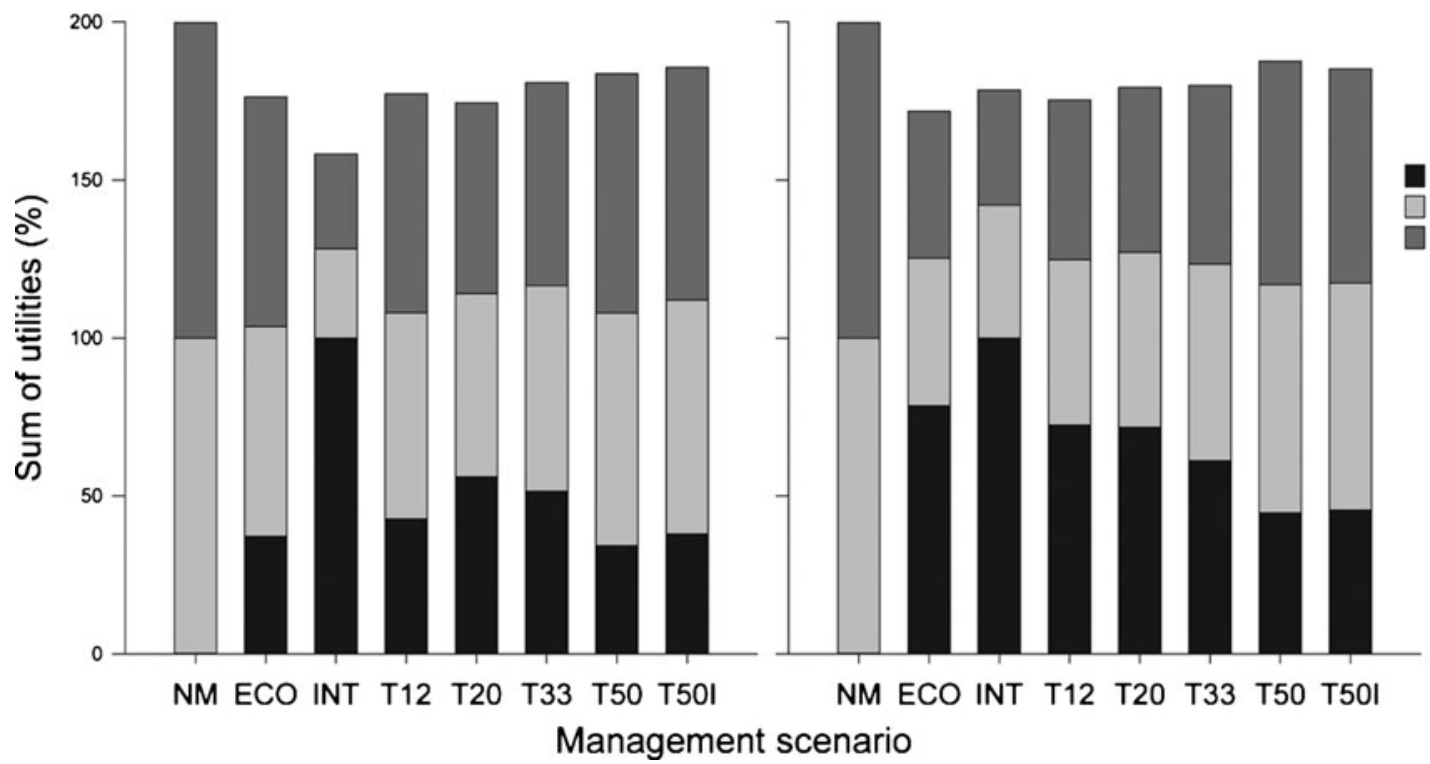

b) Shade-intolerant

deciduous stands
Timber production

Carbon storage

Habitat quality

Figure 4 Comparison of the sum of expected utilities of timber, carbon and habitat quality among three single-management and the five multiple-management TRIAD scenarios. Forest types are $(a)$ sugar maple-beech and $(b)$ shade-intolerant deciduous. The utility for one service in a given scenario is the ratio expressed as a percentage between its value for that scenario and its highest value across all scenarios. Single-management scenarios are NM = No-management; $\mathrm{ECO}=$ Ecosystem; INT = Intensive.

was measured without regard to its quality and so our method is likely to underestimate the value of timberperformant scenarios, depending on the type of products the stakeholder is interested in. The harvested species are also differentially valued on the market, their values fluctuate over time and they are highly uncertain in the future (Brazee \& Mendelsohn 1988). Measures of the quadratic mean diameter and sawlog volumes, which are available FVS outputs, could help differentiate harvesting scenarios based on the quality of timber. The integration of these additional measures and the identification of the tree species of the harvested stems would make future analyses of timber production more precise and facilitate the decision-making process.

\section{Carbon stock}

The calculation of carbon stocking as an ecosystem service was accomplished here for the purpose of comparing the performance of different management scenarios and should be seen as an estimate rather than a precise prediction. Nonetheless, our mean expected aboveground live carbon stock for SM stands reached $126.4 \pm 30.3 \mathrm{MgC} \mathrm{ha}^{-1}$, which is consistent with reported means for old-growth northern hardwood stands (Hoover et al. 2012; MacLean et al. 2014). We recognize that contemporary carbon accounting calls for a closer tracking of carbon fate in timber products (Profft et al. 2009). Carbon pools situated underground or on the forest floor (live and dead organic matter, coarse woody debris and standing dead wood) not estimated here could improve estimates (Nunery \& Keeton 2010). For example, the root biomass of hardwood trees can be 1.5-times that of aboveground biomass ( $\mathrm{Li}$ et al. 2003). However, the overall ranking of the best scenario for carbon storage is unlikely to differ if these pools were considered, since they are likely to be highly correlated with our estimate of aboveground carbon (Kurz et al. 1996). We also suggest caution in the interpretation of our carbon results since no local calibration was carried out after direct FVS computation of FIA data processed with the FIA2FVS software.

\section{Habitat quality}

Values of habitat quality, measured through our HSI, were always greater in No-management, regardless of forest type. As reported elsewhere, unmanaged stands had greater snag densities than managed ones (Vanderwel et al. 2006). Our HSI was intended to give high values to stands showing 'old-growth' characteristics (Bauhus et al. 2009). Thus, earlysuccessional stands would not display a high HSI score, even if they had high species diversity. The attributes of the HSI favoured scenarios maintaining already-present species in old uneven-aged stands and increasing late-successional species in ageing stands. Consequently, the low average habitat quality utilities of managed SID and WSP stands were anticipated. While WSP stands may provide suitable habitats for some organisms, such as generalist carabid species (Brockerhoff et al. 2008), the quality of these stands is considered inferior to more mature stands (Lindenmayer \& Hobbs 2004), which provide habitats for a wide range of species such as cavitydependent birds. However, different results could be obtained 
if emphasis was given to earlier-successional stands (Dessecker \& McAuley 2001; Brooks 2003).

\section{Managing for multiple ecosystem services}

Clear trade-offs were evident when considering multiple ecosystem services. The TRIAD scenarios provided a good compromise in terms of the amount of each of the three ecosystem services investigated. Our findings demonstrated that TRIAD scenarios can indeed achieve multiple forest management goals. With only single-management scenarios at hand, one could select Ecosystem in SM stands as a compromise between producing timber, carbon and habitat quality closest to unmanaged levels, but all stands were then subject to some level of management. Adding the TRIAD scenarios to the portfolio of possibilities revealed that it is possible to harvest as much timber as for the Ecosystem scenarios while storing, on average, a greater quantity of carbon, and having a certain proportion of the forest under total protection. As ITS in SM stands is a harvest practice of predilection in northern hardwoods (O'Hara 2002; Bédard \& Majcen 2003), this finding is most relevant and promising for future uneven-aged planning. Mean habitat quality in TRIAD may be poorer than in Ecosystem since zones under Intensive have lower HSIs. However, by limiting timber activities to a certain area and maintaining many areas totally unmanaged, the TRIAD approach may also be financially and ecologically appealing for forest owners in terms of reduction in road construction and the disturbance of some key habitats.

In our scenarios, all three ecosystem service objectives had the same weight. However, given that assigned weights should respond to stakeholder objectives, these could be modified at any point of the simulation to suit different values and interests attributed to each ecosystem service (Bengston 1994; Arnette et al. 2010). Moreover, ranking based on values that are not significantly different, or within a range of acceptability as determined by stakeholders, could be assigned a similar ranking in order to compare the variation in performance among different management scenarios (Saaty 1980; Greco et al. 2008). Alternative MCDA procedures that require a priori decision-maker preferences such as target values for each criterion in goal programming (Stewart 1992) are less user friendly. However, future modelling efforts that aim to determine optimal proportions of TRIAD zoning, for example, would benefit from the use of a continuousoptimization MCDA procedure (Estrella et al. 2014). This study focused on three important ecosystem services, but additional services of relevance to managers could also be investigated, such as the production of non-timber products (e.g. mushrooms, berries and fiddleheads) and specific recreational services. In addition, spatial configurations of TRIAD zones could be investigated in order to evaluate the effects of spatial heterogeneity, landscape fragmentation and connectivity on each service (Côté et al. 2010; Tittler et al. 2015). The parameters of forest dynamics within the FVS could be redefined according to the predicted effects of climate change that may alter tree growth and disturbance risk (Crookston et al. 2010). Moreover, the weight associated with the carbon stock utility in the MCDA could be increased in order to reflect its rising value due to the implementation of a carbon market. All of these services could also be attributed economic factors that will realistically change (e.g. an annuitized net present value) throughout the simulation period. Simplicity was an important goal of this study in order to attract new users, but future users of the model could further refine their models with such adjustments in order to improve predictions and better inform management choices.

\section{ACKNOWLEDGEMENTS}

We thank Frédéric Raulier for his constructive comments and the USDA Forest Service for technical support for the FVS.

\section{FINANCIAL SUPPORT}

Financial support for this research was provided by the Fonds de Recherche Québécois sur la Nature et les Technologies (FRQNT, grant B1-04D) and the Natural Sciences and Engineering Research Council of Canada (NSERC)'s Collaborative Research and Training Experience (CREATE, grant 398036-2011) Forest Complexity Modeling program.

\section{Supplementary material}

To view supplementary material for this article, please visit http://dx.doi.org/10.1017/S0376892916000357

\section{REFERENCES}

Ananda, J. \& Herath, G. (2009) A critical review of multicriteria decision making methods with special reference to forest management and planning. Ecological Economics 68(10): 25352548.

Arnette, A., Zobel, C., Bosch, D., Pease, J. \& Metcalfe, T. (2010) Stakeholder ranking of watershed goals with the vector analytic hierarchy process: effects of participant grouping scenarios. Environmental Modelling E Software 25(11): 1459-1469.

Badiou, P., Baldwin, R., Carlson, M., Darveau, M., Drapeau, P., Gaston, K. et al. (2013) Conserving the World's Last Great Forest is Possible: Here's How. International Boreal Conservation Science Panel. [www document]. URL http://borealscience.org/wpcontent/uploads/2013/07/conserving-last-great-forests1.pdf

Balvanera, P., Pfisterer, A. B., Buchmann, N., He, J.-S., Nakashizuka, T., Raffaeli, D. et al. (2006) Quantifying the evidence for biodiversity effects on ecosystem functioning and services. Ecology Letters 9: 1146-1156.

Bauhus, J., Puettmann, K. \& Messier, C. (2009) Silviculture for oldgrowth attributes. Forest Ecology and Management 258(4): 525537.

Bédard, S. \& Majcen, Z. (2003) Growth following single-tree selection cutting in Québec northern hardwoods. The Forestry Chronicle 79(5): 898-905. 
Belton, S. \& Stewart, T. S. (2002) Multiple Criteria Decision Analysis. An Integrated Approach. Boston, MA, USA, Kluwer Academic Publishers.

Bengston, D. N. (1994) Changing forest values and ecosystem management. Society E Natural Resources 7(6): 515-533.

Bílek, L., Remeš, J., Švec, O. \& Zahradník, D. (2013) On the way to continuous cover forest at middle elevations - the question of forest structure and specific site characteristics. Fournal of Forest Science 59(10): 391-397.

Bradford, J. B. \& D'Amato, A. W. (2011) Recognizing trade-offs in multi-objective land management. Frontiers in Ecology and the Environment 10(4): 210-216.

Brazee, R. \& Mendelsohn, R. (1988) Timber harvesting with fluctuating prices. Forest Science 34(2): 359-372.

Brockerhoff, E., Jactel, H., Parrotta, J., Quine, C. \& Sayer, J. (2008) Plantation forests and biodiversity: oxymoron or opportunity? Biodiversity and Conservation 17(5): 925-951.

Brooks, R. T. (2003) Abundance, distribution, trends, and ownership patterns of early-successional forests in the northeastern United States. Forest Ecology and Management 185(1-2): 65-74.

Brown, N. R., Noss, R. F., Diamond, D. D. \& Myers, M. N. (2001) Conservation biology and forest certification: working together toward ecological sustainability. Fournal of Forestry 99(8): 18-25.

Buongiorno, J., Dahir, S., Lu, H.-C. \& Lin, C.-R. (1994) Tree size diversity and economic returns in uneven-aged forest stands. Forest Science 40(1): 83-103.

Canadell, J. G. \& Raupach, M. R. (2008) Managing forests for climate change mitigation. Science 320(5882): 14561457.

Costanza, R., d'Arge, R., de Groot, R., Farber, S., Grasso, M., Hannon, B. et al. (1997) The value of the world's ecosystem services and natural capital. Nature 387: 253-260.

Côté, P., Tittler, R., Messier, C., Kneeshaw, D. D., Fall, A. \& Fortin, M.-J. (2010) Comparing different forest zoning options for landscape-scale management of the boreal forest: possible benefits of the TRIAD. Forest Ecology and Management 259(3): 418-427.

Crookston, N. L. \& Dixon, G. E. (2005) The Forest Vegetation Simulator: a review of its structure, content, and applications. Computers and Electronics in Agriculture 49(1): 60-80.

Crookston, N. L., Rehfeldt, G. E., Dixon, G. E. \& Weiskittel, A. R. (2010) Addressing climate change in the Forest Vegetation Simulator to assess impacts on landscape forest dynamics. Forest Ecology and Management 260(7): 1198-1211.

Dessecker, D. R. \& McAuley, D. G. (2001) Importance of early successional habitat to ruffed grouse and American woodcock. Wildlife Society Bulletin 29(2): 456-465.

Diaz-Balteiro, L. \& Romero, C. (2008) Making forestry decisions with multiple criteria: a review and an assessment. Forest Ecology and Management 255(8-9): 3222-3241.

Dixon, R. K., Solomon, A. M., Brown, S., Houghton, R. A., Trexier, M. C. \& Wisniewski, J. (1994) Carbon pools and flux of global forest ecosystems. Science 263(5144): 185-190.

Dixon, G. E. (2002) Essential FVS: a user's guide to the Forest Vegetation Simulator. Internal rep, p. 226. Fort Collins, CO, USA, Department of Agriculture, Forest, Forest Management Service Center.

Estrella, R. Cattrysse, D. \& van Orshoven, J. (2014) Comparison of three ideal point-based multi-criteria decision methods for afforestation planning. Forests 5: 3222-3240.
Ferris, R. \& Humphrey, J. (1999) A review of potential biodiversity indicators for application in British forests. Forestry 72(4): 313328.

Gini, C. (1921) Measurement of inequality of incomes. The Economic fournal 31(121): 124-126.

Greco, S., Mousseau, V. \& Słowiński, R. (2008) Ordinal regression revisited: multiple criteria ranking using a set of additive value functions. European Fournal of Operational Research 191(2): 416436.

Grumbine, E. (1994) What is ecosystem management? Conservation biology 8(1): 27-38.

Hoover, C. M., Leak, W. B. \& Keel, B. G. (2012) Benchmark carbon stocks from old-growth forests in northern New England, USA. Forest Ecology and Management 266: 108-114.

Jenkins, J. C., Chojnacky, D. C., Heath, L. S. \& Birdsey, R. A. (2003) National-scale biomass estimators for United States tree species. Forest Science 49(1): 12-35.

Kurz, W. A., Beukema, S. J. \& Apps, M. J. (1996) Estimation of root biomass and dynamics for the carbon budget model of the Canadian forest sector. Canadian Fournal of Forest Research 26(11): 1973-1979.

Li, Z., Kurz, W. A., Apps, M. J. \& Beukema, S. J. (2003) Belowground biomass dynamics in the Carbon Budget Model of the Canadian Forest Sector: recent improvements and implications for the estimation of NPP and NEP. Canadian Fournal of Forest Research 33(1): 126-136.

Lindenmayer, D. B. \& Hobbs, R. J. (2004) Fauna conservation in Australian plantation forests - a review. Biological Conservation 119(2): 151-168.

MacLean, R. G., Ducey, M. J. \& Hoover, C. M. (2014) A comparison of carbon stock estimates and projections for the Northeastern United States. Forest Science 60(2): 206-213.

McCune, B. \& Menges, E. S. (1986) Quality of historical data on Midwestern old-growth forests. American Midland Naturalist 116(1): 163-172.

Mendoza, G. A. \& Martins, H. (2006) Multi-criteria decision analysis in natural resource management: a critical review of methods and new modelling paradigms. Forest Ecology and Management 230(13): 1-22.

Messier, C., Fortin, M.-J., Schmiegelow, F., Doyon, F., Cumming, S. G., Kimmins, J. P. et al. (2003) Modelling tools to assess the sustainability of forest management scenarios. In: Tomard Sustainable Management of Boreal Forest: Emulating Nature, Minimizing Impacts and Supporting Communities, eds P. Burton, C. Messier, D. W. Smith \& V. Adamowicz, pp. 531-580. Ottawa, Canada, NRC Press.

Messier, C., Tittler, R., Kneeshaw, D. D., Gélinas, N., Paquette, A., Berninger, K. et al. (2009) TRIAD zoning in Quebec: experiences and results after 5 years. The Forestry Chronicle 85(6): 885-896.

Moore, P. T., DeRose, R. J., Long, J. N. \& van Miegroet, H. (2012) Using silviculture to influence carbon sequestration in southern Appalachian spruce-fir forests. Forests 3(2): 300-316.

Niinemets, Ü. \& Valladares, F. (2006) Tolerance to shade, drought, and waterlogging of temperate Northern hemisphere trees and shrubs. Ecological Monographs 76(4): 521-547.

Nunery, J. S. \& Keeton, W. S. (2010) Forest carbon storage in the Northeastern United States: net effects of harvesting frequency, post-harvest retention, and wood products. Forest Ecology and Management 259(8): 1363-1375. 
O'Hara, K. L. (2002) The historical development of uneven-aged silviculture in North America. Forestry 75(4): 339-346.

Odum, E. P. (1969) The strategy of ecosystem development. Science 164: 262-270.

Peng, C. (2000) Growth and yield models for uneven-aged stands: past, present and future. Forest Ecology and Management 132: 259 279.

Profft, I., Mund, M., Weber, G.-E., Weller, E. \& Schulze, E.-D. (2009) Forest management and carbon sequestration in wood products. European Fournal of Forest Research 128(4): 399413.

R Development Core Team (2010) R: A Language and Environment for Statistical Computing. Vienna, Austria, R Foundation for Statistical Computing.

Romero, C. (2001) Extended lexicographic goal programming: a unifying approach. Omega 29(1): 63-71.

Saaty, T. L. (1980) The Analytic Hierarchy Process. New York, NY, USA, McGraw-Hill.

Schamberger, M. \& Krohn, W. B. (1982) Status of the habitat evaluation procedures. Transactions of the North American Wildlife and Natural Resources Conference 47: 154-164.

Schwenk, W. S., Donovan, T. M., Keeton, W. S. \& Nunery, J. S. (2012) Carbon storage, timber production, and biodiversity: comparing ecosystem services with multi-criteria decision analysis. Ecological Applications 22(5): 1612-1627.

Stewart, T. J. (1992) A critical survey on the status of multiple criteria decision making theory and practice. Omega 20(5): 569-586.

Tamiz, M., Jones, D. \& Romero, C. (1998) Goal programming for decision making: an overview of the current state-of-theart. European Journal of Operational Research 111(3): 569 581.

Tavoni, M., Sohngen, B. \& Bosetti, V. (2007) Forestry and the carbon market response to stabilize climate. Energy Policy 35(11): 5346-5353.

Tittler, R., Filotas, E., Kroese, J. \& Messier, C. (2015) Maximizing conservation and production with intensive forest management: it's all about location. Environmental Management 56: 11041117.

Vanderwel, M. C., Caspersen, J. P. \& Woods, M. E. (2006) Snag dynamics in partially harvested and unmanaged northern hardwood forests. Canadian Fournal of Forest Research 36(11): 2769-2779.

Wykoff, W. R., Crookston, N. L. \& Stage, A. R. (1982) User's Guide to the Stand Prognosis Model. U.S. Department of Agriculture, Forest Service, Gen. Tech. Rep. INT-133, p. 112. Ogend, UT, USA, Intermountain Forest and Range Experiment Station. 